\title{
Política de cotas raciais: instrumento de promoção de equidade e justiça social
}

\author{
Racial admission quota policy: instrument for the promotion \\ of equity and social justice
}

\author{
Erica da Silva Mendonça* \\ Maria Lúcia Machado Aranha**
}

\begin{abstract}
Resumo - Este artigo aborda a política de ações afirmativas, mais especificamente, a relativa à de cotas raciais nas universidades públicas brasileiras. Resulta de uma pesquisa realizada em uma universidade pública da região Nordeste, com o objetivo de analisar a visão de discentes de diferentes cursos e centros da instituição a respeito do assunto. Fundamentada no método materialista histórico-dialético, adotou como procedimentos metodológicos as pesquisas empírica e documental, tendo como instrumentos o formulário semiestruturado para a primeira e ficha resumo, para a segunda. Os principais resultados mostraram que a posição predominante na pesquisa foi a favorável, representando $84 \%$ dos alunos pesquisados; e que há uma maior rejeição à política de cotas pelos cursos pertencentes aos centros de Ciências Biológica e da Saúde, e Ciências Exatas e Tecnologia, quando comparados aos cursos dos Centros de Ciências Sociais Aplicadas e Educação e Ciências Humanas, porém, no geral, se mostraram majoritariamente favoráveis à política em exame.
\end{abstract}

Palavras-chave: cotas raciais; negro; ensino superior; ações afirmativas.

\begin{abstract}
This article addresses the affirmative action policy, more specifically the one regarding racial admission quotas in Brazilian public universities. It is the result of a research conducted at a public university in the Brazilian Northeast region, with the objective of analyzing the point of view on this subject of students from different courses. Based on the historical-dialectical materialist method, it adopted as methodological procedures the empirical and documentary research, having as instruments the semi-structured form for the former and summary sheet for the latter. The main results showed that the predominant answer in the research was one favorable to the admission quotas, representing $84 \%$ of the students surveyed. Also, there was noted a greater rejection of the admission quota policy for courses belonging to the Biological and Health Sciences and the Exact Sciences and Technology fields, compared to the courses of the Applied Social Sciences and Education and Humanities courses. In general, though, interviewees were mostly in favor of the policy in question.
\end{abstract}

Keywords: racial quotas; black; higher education; affirmative action.

\footnotetext{
* Graduada em Serviço Social pela Universidade Federal de Sergipe (UFS). Mestranda em Serviço Social pelo Programa de Pós-Graduação em Serviço Social da UFS (PROSS/UFS). E-mail: eriicamendonca26@gmail.com. ORCID: https://orcid.org/0000-0003-0863-8773.

** Doutora em Educação pela Universidade Metodista de Piracicaba/SP (UNIMEP). Professora Titular do Departamento de Serviço Social da Universidade Federal de Sergipe (UFS). Bolsista do Programa de Educação Tutorial/ PET/MEC. E-mail: maluaranha10@gmail.com.br. ORCID: https://orcid.org/0000-0002-7058-7981.
} 


\section{Introdução}

Este artigo aborda a política de ações afirmativas, mais especificamente a relativa às cotas raciais nas universidades brasileiras. $\mathrm{O}$ estudo resulta de pesquisa realizada em uma universidade pública da região Nordeste, com o objetivo de analisar a visão de discentes de diferentes cursos e centros da instituição a respeito do assunto. Partindo-se da observação do cotidiano, notamos que a política de cotas é um tema bastante polêmico, que divide opiniões entre pessoas contrárias e favoráveis, e que, consequentemente, possuem diferentes argumentos para a defesa de seus pontos de vista.

Entre os argumentos contrários às cotas raciais, encontra-se a alegação de que elas desconsideram o critério do mérito, mecanismo bastante exaltado nas normas morais da sociedade. Dessa maneira, segundo os seus defensores, leva até mesmo a uma discriminação reversa que aumenta o racismo (ANDREWS, 1997 apud BAYMA, 2012). Porém, a discussão sobre a meritocracia deixa de lado as condições socioeconômicas de um grande segmento da população negra até o momento de disputa das vagas nas universidades, se caracterizando por uma visão conservadora.

A Lei no 12.711 (BRASIL, 2012), que dispõe sobre o ingresso nas universidades federais e nas instituições federais de ensino técnico de nível médio, estabelece em seu artigo $1^{\circ}$ que essas instituições de ensino deverão reservar no mínimo 50\% das vagas, por curso e turno, para estudantes advindos de escola pública, das quais 50\% devem ser destinadas a alunos oriundos de famílias com renda igual ou inferior a um salário mínimo e meio. Declara, ainda, que os outros $50 \%$ serão preenchidos pelos autodeclarados pretos, pardos e indígenas e pessoas com deficiência, desde que observada a proporção dessa população na unidade da Federação de cada instituição, de acordo com o último censo do Instituto Brasileiro de Geografia e Estatística (IBGE).

É inegável a dívida histórica existente com a população negra por mais de três séculos de escravidão a que foi submetida, cenário que gerou a desigualdade observada ainda hoje. Faz-se necessário, portanto, buscar medidas de democratização do acesso ao ensino superior, além de outras ações em áreas distintas, para que gradativamente esse segmento saia do lugar secular que lhe foi imposto. Segundo Januário (2014, n. p.):

\footnotetext{
Além da dívida histórica que o país tem com os afrodescendentes por anos de exploração, a lei veio para minimizar as diferenças raciais e socioeconômicas que sempre existiram no Brasil. Aqui, somente $47,73 \%$ dos brasileiros se declaram brancos, segundo o Censo de 2010, tornandose assim um dos países mais miscigenados do mundo. Mesmo com toda essa mistura ainda há diferenças que gritam aos nossos olhos.
} 


\section{ReVIStg a d P paUt?}

\} POLÍTICA DE COTAS RACIAIS - MENDONÇA, E. S.; ARANHA, M. L. M. \}

DOI: $10.12957 /$ REP.2020.47226

Assim, as cotas se tornam uma medida urgente pelo fato de que esperar por uma reforma no ensino público básico que coloque o negro em pé de igualdade para competir com o estudante branco de classe média de escola particular levaria anos, deixando as estatísticas inalteradas durante muito tempo ainda. A situação é muito díspar: em 2005 a porcentagem de negros cursando o ensino superior era de $5,5 \%$ do total de negros no Brasil; em 2015, esse número subiu para 12,8\%; já entre os brancos, em 2005, esse número era de 17,8\% e, em 2015, 26,5\%, segundo o IBGE (VIEIRA, 2016). Esses números revelam que, mesmo depois de implementada a política de cotas raciais, a diferença entre negros e brancos acessando o ensino superior ainda é elevada.

O método que deu base à realização da pesquisa foi o materialismo histórico-dialético, por possibilitar a apreensão da temática a partir da perspectiva de totalidade, captando-se uma multiplicidade de determinantes por meio de aproximações sucessivas ao objeto. Ademais, em termos de procedimentos metodológicos, a pesquisa foi de caráter quali-quantitativo, com a utilização de dados tanto textuais, obtidos com a utilização das pesquisas bibliográfica e documental, quanto verbais, coletados com aplicação de formulário semiestruturado na pesquisa empírica.

A população da pesquisa foi composta por estudantes de diferentes cursos e centros da instituição de ensino superior (IES) pesquisada. Para a coleta dos dados foram utilizados quatro dos cinco centros da IES: Centro de Ciências Sociais Aplicadas (Serviço Social e Direito), Centro de Educação e Ciências Humanas (História e Pedagogia); Centro de Ciências Exatas e Tecnologia (Ciência da Computação e Engenharia Civil); e Centro de Ciências Biológicas e da Saúde (Enfermagem e Medicina). De cada curso foram entrevistados sete alunos, totalizando uma amostra de 56 pesquisados, correspondendo a 1,44\% do universo total de alunos ativos nesses cursos (3.887 alunos).

O texto se constitui de três seções, além desta introdução e das considerações finais. A primeira traz uma breve abordagem da história do negro no Brasil, desde a Escravidão até os dias atuais; a segunda é dedicada à política de cotas e foca na sua implementação na Universidade Federal de Sergipe, por ser a primeira do Nordeste a adotá-la; e a terceira apresenta os principais resultados da pesquisa.

\section{O negro na sociedade brasileira}

Entre os séculos XVI e XVIII, enquanto a Europa já estava implementando o trabalho livre, com o processo de industrialização, no Brasil ocorria a implementação do trabalho escravo, devido à expansão da agricultura, principalmente com o cultivo da cana-de-açúcar. Era o próprio processo de acumulação primitiva, gerador das condições para o capitalismo industrial (nos países europeus), que fazia surgir aqui a escravidão. E assim foi se ges- 


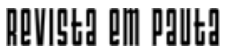

\} POLÍTICA DE COTAS RACIAIS - MENDONÇA, E. S.; ARANHA, M. L. M. \}

DOI: $10.12957 /$ REP.2020.47226

tando o trabalho escravo nas colônias, inclusive no Brasil, na medida em que eram desenvolvidas as produções de gêneros agrícolas (açúcar, algodão, tabaco) e metais preciosos (ouro e prata), revertendo-se em lucros para a metrópole se desenvolver economicamente (IANNI, 1988).

No século XVIII, o Brasil começou a sofrer pressões da Inglaterra para abolir a escravidão em suas terras, pois a Inglaterra estava adentrando no período de Revolução Industrial. Logo, precisava de um mercado consumidor maior, ou seja, precisava que os escravos fossem libertos e transformados em trabalhadores assalariados para consumirem os produtos industrializados vindos da Europa.

Os mercados nacionais e internacionais passaram a ser inundados também por produtos manufaturados, em quantidades crescentes e nas mais diversas qualidades e modas. As colônias europeias passaram a receber, em quantidades crescentes, as manufaturas inglesas. O capital industrial impunha-se sobre o comercial e o financeiro. Assim, ao longo dos séculos XVI a XVIII foi crescendo a importância da produção industrial [...]. Mas foi no século XVIII que o capital industrial conquistou a preeminência sobre o capital comercial. Foi uma transição histórico-estrutural complexa, na qual o capital produtivo passou a colorir e dar sentido ao conjunto das relações de produção e do processo de realização da mercadoria. (IANNI, 1988, p. 36).

Acabar com o tráfico foi o pontapé inicial para a decadência da escravidão no Brasil, e a partir de então começaram a ser tomadas medidas para evitar que o liberto fosse integrado social e economicamente à sociedade. Quando a escravidão foi finalmente abolida, os negros não foram absorvidos pelo mercado de trabalho; muito pelo contrário, foram deixados às margens da inserção social, sem um lugar para morar, sem emprego, sem direitos essenciais, restando a eles a marginalidade e a formação de morros e favelas. Como destaca Theodoro (2008, p. 24-25):

Não houve a valorização dos antigos escravos ou mesmo dos livres e libertos com alguma qualificação. O nascimento do mercado de trabalho ou, dito de outra forma, a ascensão do trabalho livre como base da economia foi acompanhada pela entrada crescente de uma população trabalhadora no setor de subsistência e em atividades mal remuneradas. Esse processo vai dar origem ao que, algumas décadas mais tarde, viria a ser denominado 'setor informal', no Brasil.

Ao invés de contratar trabalhadores negros libertos, os proprietários das fábricas e empresas priorizaram a mão de obra imigrante (IANNI, 1966). Esse fator, se caracterizando como uma forma de discriminação racial, contribuiu bastante para o cenário de exclusão da população negra que podemos ver até hoje. Rejeitado pelo mercado formal de trabalho, o negro ficou à margem da sociedade e encontrou como alternativa o trabalho informal para o seu sustento. 
Mais do que uma decisão racional do empresário capitalista, a passagem da escravidão ao trabalho livre parece ser parte de um processo mais amplo de reestruturação econômica e social, mas também de um aprofundamento da inserção da economia brasileira no contexto mundial (cf. SINGER, 1975, p. 353). Contudo, outros fatores importantes, já citados anteriormente, influíram nesse processo: o nascimento e consolidação de uma visão eurocêntrica e modernizante, na qual, para o negro, não havia, ou havia pouco espaço de existência. (THEODORO, 2008, p. 32).

Depois de séculos vivendo em privação de liberdade e regime de trabalho escravo, sem nenhuma perspectiva de vida, bens materiais ou possibilidades de ascensão social, como poderiam os escravos libertos ter condições mínimas de sobrevivência em uma sociedade que não lhes ofereceu oportunidades, sem a criação de mecanismos para que fossem inseridos socialmente? "[...] o acesso à instrução também não fora garantido por políticas públicas, não sendo sequer acolhido como objetivo ou garantia de direitos na Constituição Republicana de 1891" (THEODORO, 2008, p. 33). O espaço que lhes restou foi vagar pelas cidades, ocupar os morros criando as favelas, os cortiços e exercendo os trabalhos menos prestigiados.

O racismo se manifestou de forma mais acirrada após a abolição da escravatura, o que pode estar associado ao fato de que, estando libertos, os negros poderiam ocupar os mesmos espaços de convivência dos brancos e ascender socialmente, alcançando a mobilidade social, não fossem o preconceito, a discriminação e o racismo sofridos pelos primeiros. Por isso, os brancos buscaram justificativas para reafirmar sua superioridade a qualquer custo e em várias áreas, até mesmo na ciência.

[...] o racismo, que nasce no Brasil associado à escravidão, consolida-se após a abolição, com base nas teses de inferioridade biológica dos negros, e difunde-se no país como matriz para a interpretação do desenvolvimento nacional. As interpretações racistas, largamente adotadas pela sociedade nacional, vigoraram até os anos 30 do século XX e estiveram presentes na base da formulação de políticas públicas que contribuíram efetivamente para o aprofundamento das desigualdades no país. (THEODORO, 2008, p. 24).

Apesar de ainda permanecer vivo e forte, o racismo é negado por muitos, ao afirmarem que vivemos em uma democracia racial. Isso diz respeito à ideia de que não existe preconceito racial ou discriminação por conta da cor da pele na sociedade brasileira. E, apesar de, à primeira vista, aparentar ser um avanço em direção à igualdade racial no país, essa ideia acaba sendo um retrocesso na conquista de direitos e espaço por parte desse segmento da população. Através desse (democracia racial) e de outros mecanismos, o governo se exime da criação de políticas sociais que promovam a igualdade racial, deixando a população negra majoritariamente estática, sem condições de mobilidade social ou melhorias em sua qualidade de vida. 


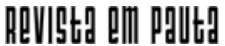

\} POLÍTICA DE COTAS RACIAIS - MENDONÇA, E. S.; ARANHA, M. L. M. \}

DOI: $10.12957 /$ REP.2020.47226

A exemplo disso, "Em 1970, o Ministro das Relações Exteriores declara que 'não há discriminação racial no Brasil, não há necessidade de tomar quaisquer medidas esporádicas de natureza legislativa, judicial ou administrativa para assegurar a igualdade de raças no Brasil'" (TELLES, 2003 apud JACCOUD, 2008, p. 52). Entretanto, a dita democracia racial não passa de um mito, pois

\begin{abstract}
estereótipos e preconceitos raciais continuariam atuantes na sociedade brasileira durante todo o período, intervindo no processo de competição social e de acesso às oportunidades, assim como influenciando no processo de mobilidade intergeracional, restringindo o lugar social dos negros. [...] o racismo opera um mecanismo de desqualificação dos não-brancos na competição pelas posições mais almejadas. (JACCỎUD, 2008, p. 52).
\end{abstract}

A exclusão em níveis elevados dessa população na sociedade é um fato sustentado pelas estatísticas, que mostram os negros sempre ocupando os piores lugares nos mais variados índices, como emprego, educação e renda, bem como os lugares mais altos quando se trata de índices de violência e desemprego, por exemplo. A população negra representa $78,9 \%$ de $10 \%$ dos indivíduos que possuem mais chances de serem vítimas de homicídio; o número de mulheres negras assassinadas cresceu 54\% de 2003 a 2013, enquanto que o mesmo índice de mulheres brancas caiu 10\% no mesmo período. Com relação à violência doméstica, as mulheres negras representaram 58,68\% em 2015; violência obstétrica, 65,4\%; e mortalidade materna, $53,6 \%$. Atualmente, a cada 100 pessoas assassinadas no Brasil, 71 são negras, e dos 622 mil brasileiros presos, 61,6\% são pretos e pardos. Quando tratamos do desemprego, 63,7\% dos desempregados são negros, o que representa uma taxa de $14,6 \%$ de desemprego entre eles, enquanto temos $9,9 \%$ de desempregados entre os brancos (OLIVEIRA, 2017).

Dessa forma, é importante evidenciar a realidade na qual à população negra é negada uma série de direitos e oportunidades por conta do racismo presente na sociedade brasileira. Portanto, é necessária a criação de políticas públicas para esse segmento, como é o caso da política de cotas raciais, que promove a inclusão da população negra em diversos espaços, com destaque, no caso desse trabalho, para a política de cotas raciais no ensino superior.

\section{Política de cotas raciais na universidade pública brasileira}

No contexto brasileiro, a política de ações afirmativas se configura, segundo Pena (2010), em medidas que promovem a elevação de certos grupos que se encontram em posição de desvantagem por conta de discriminações. Essas medidas, por sua vez, são "[...] aptas a proporcionar uma transformação social e cultural e implantar uma maior diversidade e pluralismo nos diversos ramos da atividade pública e privada" (PENA, 2010, p. 7). 


\section{ReVIStg a d P paUt?}

\} POLÍTICA DE COTAS RACIAIS - MENDONÇA, E. S.; ARANHA, M. L. M. \}

DOI: $10.12957 /$ REP.2020.47226

Salienta-se que as cotas não são a única política de ação afirmativa, apesar de muitas vezes estes conceitos serem confundidos. As ações afirmativas vão muito além das cotas e se estendem em ações relacionadas a gênero, deficiências físicas etc. No caso das cotas nas universidades, o que ocorre é apenas a reserva de vagas, o que não garante a permanência do aluno, de modo que há a necessidade de outras políticas nesse percurso, como a de assistência estudantil.

A política de cotas raciais é uma ação afirmativa, pois tem por objetivo criar, através da discriminação positiva, a igualdade material entre brancos e negros para o acesso ao ensino superior público. A Lei no 12.711 , de 29 de agosto de 2012, que dispõe sobre o ingresso nas universidades e nas instituições federais de ensino técnico de nível médio, estabelece em seu artigo $1^{\circ}$ que as instituições federais de educação superior deverão reservar, no mínimo, $50 \%$ de suas vagas para os estudantes que cursaram todo o ensino médio em escolas públicas. Destes, $50 \%$ devem ser destinados a estudantes advindos de famílias com renda igual ou inferior a um salário mínimo e meio per capita. No referente aos negros, indígenas e pessoas com deficiência, as vagas devem ser reservadas ainda dentro dos primeiros 50\%, obedecendo à proporção de pretos, pardos, indígenas e pessoas com deficiência na população do estado onde está localizada a instituição de ensino, de acordo com o último censo do Instituto Brasileiro de Geografia e Estatística (IBGE) (BRASIL, 2012).

A primeira universidade do Nordeste a implementar a política de cotas foi a Universidade Federal de Sergipe (UFS), por isso, e por ter sido o campo empírico da pesquisa, trataremos dela neste tópico, abordando como se deu essa implementação, desde as primeiras iniciativas. Os primeiros debates sobre a possibilidade de implementação da política de cotas na UFS ocorreram no final dos anos 1990 e tinham o Núcleo de Estudos AfroBrasileiros (Neab) como grande incentivador.

Porém, a aprovação da implementação de tal política ocorreu somente em 2008, com a "[...] reserva de vagas para alunos oriundos de escolas públicas (com corte racial proporcional à composição da população em termos de cor da pele) [...]" (NEVES, 2010, p. 18), e passou a valer apenas a partir do vestibular para ingresso em 2010. Esse longo período entre o início da discussão e a efetiva implementação da política pode estar relacionado à grande polêmica e divisão de opiniões que envolvem esse debate, pois é um "[...] Divisor de águas do debate sobre o preconceito racial [...] a temática das cotas universitárias vai dividir as opiniões tanto no interior quanto no exterior das universidades" (NEVES, 2010, p. 17).

Anteriormente à efetivação da política de cotas na Universidade Federal de Sergipe, foram realizadas pesquisas para entender os níveis de acesso a esta universidade de acordo com o público, se eram em sua maioria alunos da rede pública (municipal, estadual ou federal) ou da rede privada. Além disso, foram contabilizados também os candidatos no processo de 


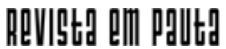

\} POLÍTICA DE COTAS RACIAIS - MENDONÇA, E. S.; ARANHA, M. L. M. \}

DOI: $10.12957 /$ REP.2020.47226

vestibular, fazendo uma média entre candidatos e aprovados, tendo por base de análise os anos de 2007 e 2008, com o objetivo de subsidiar a implementação dessa política na referida instituição de ensino superior. Através dessa pesquisa foi possível apreender que,

[...] apesar do número total de alunos concluintes do Ensino Básico da rede privada ser bem menor que os concluintes do Ensino Básico da rede pública, uma proporção consideravelmente bem maior de alunos oriundos da escola privada ingressaram na universidade pública, estando estes super-representados na relação com os oriundos da escola pública. (MARCON, 2010, p. 38-39).

Fazendo um recorte de alunos do ensino médio no vestibular da UFS em 2008, temos os seguintes dados: $2,49 \%$ dos candidatos foram de escola pública municipal; $47,24 \%$ de escola pública estadual; $4,40 \%$ de escola pública federal e $45,86 \%$ de escola privada. Entre os aprovados, 2,39\% eram de escola pública municipal; 36,03\% de escola pública estadual; 7,35\% de escola pública federal e $54,22 \%$ de escola privada. Tais dados demonstram com clareza a distorção do acesso ao ensino público superior entre alunos da rede pública e privada. As escolas públicas, mesmo com maior número de candidatos, possuem um menor número de aprovados com relação aos alunos de escolas particulares. Outra observação importante a ser feita referese aos alunos que terminam o ensino médio em escolas públicas, mas não chegam nem a tentar o vestibular da universidade federal, como demonstra Marcon (2010, p. 46-47):

[...] foram 12.902 alunos egressos das redes municipal e estadual em 2006 e apenas 9.768 deles realizaram o concurso vestibular na UFS, sendo que os egressos da rede particular no mesmo ano foram 2.759 alunos, mas inversamente perfaziam um total de 9.431 inscritos no vestibular (quase 4 vezes mais o número de concluintes do Ensino Médio da rede privada naquele ano). Isto demonstra que o aluno de escola pública estava proporcionalmente muito menos estimulado a tentar o vestibular na UFS, enquanto os alunos da rede privada ingressavam por ano quase na mesma proporção em que se formavam na rede privada, que no ano em questão totalizara 2.169 alunos, muito distante da proporção de 12.902 alunos que concluíram, naquele ano, o Ensino Médio em escola pública estadual e municipal.

Esses dados demonstram ainda que, muito mais do que "menos estimulado a tentar o vestibular na UFS", o aluno de escola pública precisa ingressar mais rapidamente no mercado de trabalho, pois não tem uma estrutura econômica familiar tão fortemente estabelecida como a maioria dos alunos egressos de escolas privadas, que podem continuar apenas estudando durante todo o ano para tentar novamente o vestibular no ano seguinte.

Dos cursos de Odontologia, Direito Bacharelado (noturno), Medicina, Direito Bacharelado (diurno), Arquitetura/Urbanismo, Nutrição Bacha- 


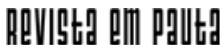

\} POLÍTICA DE COTAS RACIAIS - MENDONÇA, E. S.; ARANHA, M. L. M. \}

DOI: $10.12957 /$ REP.2020.47226

relado, Enfermagem Bacharelado, Fonoaudiologia Bacharelado, Engenharia Mecânica, Engenharia Elétrica, Engenharia de Produção, Engenharia Civil, Biologia Bacharelado, Fisioterapia Bacharelado e Zootecnia Bacharelado, todos tiveram mais de $80 \%$ dos alunos oriundos de escolas da rede privada de ensino, sendo que Odontologia, Direito (noturno e diurno) e Medicina totalizam mais de $94 \%$ de alunos de escolas privadas. Demonstra-se, assim, "[...] um quadro elitista no que diz respeito ao acesso à educação superior" (MARCON, 2010, p. 48). No "quesito étnico-racial" dos candidatos,

[...] de um total de 21.226 inscritos, em 2008, 6.576 declararam cor ou raça branca, 11.525 parda, 2.863 negra, 38 oriental e 224 indígena. Dos 4.011 aprovados no mesmo vestibular 1.377 eram de cor ou raça branca declarada, 2.099 parda, 498 negra, 4 oriental e 33 indígena. (MARCON, 2010, p. 49).

Estes dados demonstram como, no ano de 2008, ainda era desigual o acesso ao ensino público superior, tanto em relação aos alunos oriundos de escolas públicas, quanto aos negros e indígenas, reforçando a necessidade de implementação da política de cotas na UFS. Na proposta criada pela Comissão de Ações Afirmativas da UFS e pelo Núcleo de Estudos Afro-Brasileiros, foram priorizadas questões como "[...] o comprometimento de uma instituição pública, com a agenda contemporânea, que exige responsabilidades institucionais em resposta aos cenários de desigualdades socioeconômicas e raciais que imperam visivelmente na própria instituição e na sociedade brasileira e sergipana" (MARCON, 2010, p. 51). Logo, a proposta aprovada foi estruturada da seguinte forma:

Reserva de $50 \%$ das vagas totais de todos os cursos de graduação para os candidatos que tenham cursado integralmente o ensino médio e pelo menos quatro anos do ensino fundamental em instituições públicas de ensino. [...] No caso da falta de classificados, as vagas retornam à classificação geral. [...] reserva de $70 \%$ destas vagas para estudantes da escola pública que se auto-declararem pardos, pretos ou indígenas, e que no momento da inscrição para o vestibular optarem pela reserva de vagas étnico-raciais. [...] Por último [...] a reserva de uma vaga por curso para candidatos deficientes [...]. (MARCON, 2010, p. 52-53).

Tendo ficado estabelecida desta maneira, vamos analisar no próximo tópico a visão dos discentes sobre essa política.

\section{A visão dos discentes da Universidade Federal de Sergipe sobre as cotas raciais}

Neste tópico nos deteremos na análise dos resultados da pesquisa, procurando explicitar os principais argumentos do debate acerca das cotas 


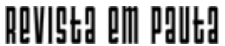

\} POLÍTICA DE COTAS RACIAIS - MENDONÇA, E. S.; ARANHA, M. L. M. \}

DOI: $10.12957 /$ REP.2020.47226

raciais. Os cursos estão distribuídos para compor quatro centros da Universidade Federal de Sergipe, sendo que temos dois cursos de cada centro: Centro de Ciências Biológicas e Saúde (CCBS), com Enfermagem e Medicina; Centro de Ciências Exatas e Tecnologia (CCET), com Ciência da Computação e Engenharia Civil; Centro de Ciências Sociais Aplicadas, com Direito e Serviço Social; e Centro de Educação e Ciências Humanas, com História e Pedagogia. Foram aplicados sete formulários em cada curso, ou seja, 14 por centro, totalizando 56 discentes.

A maioria dos estudantes pesquisados é favorável à política de cotas raciais, representando um total de $84 \%$; os não favoráveis representam 16\%. Segundo Neves (2010), com relação à Universidade Federal de Sergipe, desde antes da implementação da política de cotas na instituição até hoje, as opiniões vêm mudando e a proporção favorável à política de cotas cresce, fato que pode estar ligado a diversos fatores, como "[...] a tomada de posição do governo federal em favor das cotas universitárias [...] mudanças na composição de forças no seio do movimento estudantil a nível local [...] e do movimento sindical dos professores da UFS, cuja entidade representativa passa a apoiar as cotas sociais [...]" (NEVES, 2010, p. 30).

Dessa forma, cria-se todo um clima favorável à implementação da política de ação afirmativa, o que recebe uma forte influência de posições de entidades representativas importantes dentro da universidade. Claro que as opiniões contrárias continuarão existindo, porém, de uma forma "velada", como bem observa o autor. Segundo ele: "No fundo, o que essas posturas revelam é o fato de que se tornou politicamente incorreto ser contrário às políticas afirmativas na universidade, sob o risco de parecer insensível às desigualdades da sociedade brasileira" (NEVES, 2010, p. 31). Portanto, as pessoas que são contrárias à política de cotas repensam suas opiniões ou as escondem.

Com relação à análise de opiniões por centros, verificamos que, mesmo que de forma não tão expressiva, o CCBS e o CCET se destacam quanto à não concordância com a política de cotas, e, quando somados os valores desses centros, representam $42,86 \%$ de opiniões negativas, enquanto que o CCSA e o CECH representam 21,43\% de opiniões contrárias. Quando relacionamos as opiniões por curso, percebemos que as porcentagens se repetem nos cursos de Ciência da Computação, Direito, História, Medicina e Pedagogia, com $85,71 \%$ favoráveis e $14,29 \%$ não favoráveis em cada um dos cursos citados. O número de não favoráveis aumenta nos cursos de Enfermagem e Engenharia Civil, fazendo o percentual chegar a 28,57\%. Já o curso de Serviço Social apresenta 100\% de alunos favoráveis à política de cotas raciais, fato que possivelmente está ligado às características do curso, cuja profissão possui um projeto ético-político voltado à defesa dos interesses da classe trabalhadora, além do das minorias, que devem ter seus direitos respeitados, como explicitado nos princípios fundamentais números $\mathrm{V}, \mathrm{VI} \mathrm{e}$ XI do Código de Ética do assistente social (CFESS, 2012, n. p.): 
V. Posicionamento em favor da equidade e justiça social, que assegure universalidade de acesso aos bens e serviços relativos aos programas e políticas sociais, bem como sua gestão democrática; VI. Empenho na eliminação de todas as formas de preconceito, incentivando o respeito à diversidade, à participação de grupos socialmente discriminados e à discussão das diferenças; [...] XI. Exercício do Serviço Social sem ser discriminado/a, nem discriminar, por questões de inserção de classe social, gênero, etnia, religião, nacionalidade, orientação sexual, identidade de gênero, idade e condição física.

Com relação às justificativas dos pesquisados a respeito das posições favoráveis à política de cotas raciais, para efeito de análise, as respostas foram agrupadas de acordo com os seus elementos comuns, estabelecendose as seguintes categorias: pela dívida histórica $(26,39 \%)$; pela democratização do acesso ao ensino público superior $(23,71 \%)$; pela educação pública deficitária $(9,72 \%)$; pela falta de oportunidades $(18,06 \%)$; como medida temporária $(5,56 \%)$; pela desigualdade social $(11,11 \%)$; pelo mito da democracia racial (1,39\%); pela falha da meritocracia em um sistema desigual $(1,39 \%)$; e apenas quando as cotas raciais estão dentro das sociais $(2,78 \%)$.

A justificativa apoiada na dívida histórica foi a mais utilizada, representando a opinião de $26,39 \%$ dos pesquisados. Ela também é encontrada na literatura, como abordado na introdução deste trabalho. Essa dívida histórica se constitui por conta do longo período de escravidão ao qual a população negra foi submetida, tema tratado no primeiro tópico deste trabalho. Em segundo lugar está a democratização do acesso ao ensino superior, que se faz necessária diante da realidade de exclusão à qual está submetida essa população, já que, "[...] somente 12,8\% dos estudantes em instituições de ensino superior brasileiras, entre 18 e 24 anos de idade, são negros (pretos e pardos), de acordo com dados do Instituto Brasileiro de Geografia e Estatística (IBGE), referentes a 2015" (UFJF, 2017, n. p.).

Posteriormente, em terceiro lugar, aparece como uma das justificativas mais utilizadas a falta de oportunidades $(18,06 \%)$ ocasionada pela desigualdade social $(11,11 \%)$, também apontada como justificativa pelos alunos pesquisados. Em seguida, temos o apoio por conta da educação pública deficitária $(9,72 \%)$; apenas como uma medida temporária $(5,56 \%)$; apenas quando as cotas raciais estão dentro das sociais (2,78\%); pelo mito da democracia racial $(1,39 \%)$ e pela falha da meritocracia em um sistema desigual $(1,39 \%)$.

Da mesma forma que foram agrupadas as justificativas favoráveis, as opiniões contrárias à política de cotas raciais foram categorizadas de acordo com seus elementos em comum, ficando estabelecidas as seguintes categorias: porque há um conformismo com o estabelecimento dessa política $(8,33 \%)$; por não existir uma estrutura de suporte ao cotista dentro da universidade $(8,33 \%)$; por apontar as cotas raciais como discriminatórias $(8,33 \%)$; por concordar apenas com cotas sociais (33,33\%); por afirmar que 


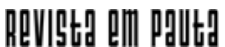

\} POLÍTICA DE COTAS RACIAIS - MENDONÇA, E. S.; ARANHA, M. L. M. \}

DOI: $10.12957 /$ REP.2020.47226

a cor da pele não tem impacto nas condições educacionais, apenas as condições socioeconômicas (16,67\%); por acreditar que a solução está na meIhoria do ensino público e no combate ao preconceito e racismo (25\%).

Nessa categoria, a justificativa que apareceu em maior evidência é a de que concordam apenas com as cotas sociais, equivalendo a 33,33\% das respostas. Esta, por sua vez, pode se articular com a justificativa que apareceu em terceiro lugar, em $16,67 \%$ das respostas: "afirma que a cor da pele não tem impacto nas condições educacionais, apenas as condições socioeconômicas", pois as pessoas que defendem essa justificativa muito provavelmente são a favor apenas das cotas sociais em detrimento das raciais. É importante ressaltar que evidentemente a cor da pele não define a capacidade de aprendizado de alguém, porém, a condição de exclusão atribuída pela sua cor/raça, sim.

Em segundo lugar encontramos a defesa da melhoria no ensino público e o combate ao preconceito e racismo, em $25 \%$ das respostas, o que evidentemente deve ser feito. Entretanto, isso não anula a necessidade de uma ação urgente que traga oportunidades à população negra em um prazo menor, pois esta já se encontra há muitos anos subalternizada; as medidas, portanto, devem ser urgentes.

Em seguida apareceram outras três justificativas com 8,33\% cada. São elas: "porque há um conformismo com o estabelecimento dessa política"; "aponta as cotas raciais como discriminatórias" e "por não existir uma estrutura de suporte ao cotista dentro da universidade. Sobre esta última é significativo destacar que há na UFS uma política de assistência estudantil que visa dar apoio a estudantes em situação de vulnerabilidade social, entre eles os cotistas, através de bolsas, residência universitária etc., porém, ela não consegue alcançar a todos que dela necessitam, o que se aprofunda ainda mais no cenário de cortes no orçamento público, incluindo a educação.

Com relação às discussões sobre a sociedade brasileira, com exceção do curso de Enfermagem, todos os outros apresentaram unanimidade nas respostas, sejam negativas ou positivas. $100 \%$ dos alunos dos dois cursos do Centro de Ciências Exatas e Tecnologia (Ciência da Computação e Engenharia Civil) foram unânimes ao afirmar que seus cursos não proporcionam essas discussões. Já nos cursos de Direito, História, Medicina, Pedagogia e Serviço Social, $100 \%$ dos alunos afirmaram que os cursos proporcionam tais discussões. No caso dos cursos de Enfermagem (42,86\%) e Medicina $(57,14 \%)$, as respostas positivas estavam ligadas, em sua maioria, às discussões sobre o Sistema Único de Saúde e saúde pública.

\section{Considerações finais}

O percurso da discussão travada neste trabalho encaminha-se no sentido de explicitar a trajetória histórica de exploração e negação de direitos 


\section{ReVIStg a d P p putt}

\} POLÍTICA DE COTAS RACIAIS - MENDONÇA, E. S.; ARANHA, M. L. M. \}

DOI: $10.12957 /$ REP.2020.47226

a que foi submetida a população negra durante mais de três séculos de escravidão, bem como a atualidade da sua condição de subalternidade na sociedade brasileira, com foco na política de cotas para o ensino superior. Além disso, traz dados sobre o acesso a esse espaço de socialização e a visão dos discentes da Universidade Federal de Sergipe sobre tal política.

A política de cotas raciais é um exemplo de ação concreta que vem sendo implementada no Brasil e, apesar de sua lei ter sido estabelecida apenas em 2012, já havia algumas universidades executando-a antes disso, inclusive a Universidade Federal de Sergipe, que aprovou o estabelecimento dessa política no ano de 2008, pondo em vigor no vestibular para ingresso em 2010. Essa ação levantou e ainda levanta debates polêmicos com uma grande diversidade de opiniões divergentes, debates esses que foram analisados neste trabalho a partir da exposição das posições e justificativas dos estudantes no que se refere a essa política.

Apontamos como principais resultados obtidos a partir da pesquisa realizada a posição majoritariamente favorável à política de cotas raciais, com $84 \%$ de aprovação, o que demonstra um reordenamento do modo de apreender as questões ligadas à sociedade segundo uma perspectiva mais crítica, particularmente com relação à desigualdade de acesso à universidade pública, conforme aqui discutido. Destacamos também a maior concentração de respostas favoráveis nos cursos pertencentes aos centros de ciências humanas $(85,71 \%)$ e sociais $(92,86 \%)$, em detrimento dos cursos ligados às ciências biológicas $(78,57 \%)$ e exatas $(78,57 \%)$. Merece destaque o curso de Serviço Social, por ter sido o único curso que apresentou em seus resultados resposta unânime (100\%) favorável às cotas raciais, o que demonstra a força do seu projeto ético-político, exercendo influência na formação da perspectiva crítica dos discentes.

Com relação às justificativas, as que mais se sobressaíram no caso das favoráveis foram às que afirmam a defesa pela dívida histórica $(26,39 \%)$ e pela democratização do acesso ao ensino superior (23,61\%). Demonstra-se, portanto, a capacidade de análise dialética dos pesquisados, que estabeleceram relação entre a situação atual e a história vivida pela população negra.

Quanto às justificativas não favoráveis, aparecem em evidência a defesa de cotas que avaliem apenas o caráter socioeconômico do estudante, ou seja, cotas sociais (33,33\%), e a melhoria do ensino público aliado ao combate ao racismo e preconceito (25\%). Estas, por sua vez, desconsideram a história e o longo tempo que essa população ainda seria submetida caso fosse esperar apenas pela melhoria no ensino público básico, tendo em vista que, mesmo com as cotas, o processo ainda é lento. É evidente que a melhoria da educação pública básica deve ocorrer; porém, medidas urgentes são necessárias para que esse quadro de exclusão não se perpetue por mais tempo.

A respeito das discussões sobre a realidade brasileira, que podem levar a reflexões pertinentes sobre diversos temas relevantes socialmente, notamos que tanto os estudantes favoráveis quanto os não favoráveis à política 


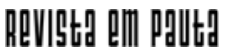

\} POLÍTICA DE COTAS RACIAIS - MENDONÇA, E. S.; ARANHA, M. L. M. \}

DOI: $10.12957 /$ REP.2020.47226

de cotas raciais apontaram que seus cursos proporcionam esse tipo de discussão: $72,34 \%$ no caso dos favoráveis e 55,56\% no caso dos não favoráveis. Todavia, esse número é consideravelmente maior entre os favoráveis, demonstrando a importância de serem travadas discussões transversais nos cursos, que ultrapassem a mera passagem de conhecimentos técnicos da profissão.

Chamamos a atenção para a importância de levar temas como esse para discussão em todos os cursos, não apenas nos cursos das ciências humanas e sociais, já que todos convivemos em sociedade e no dia a dia da formação acadêmica e do exercício profissional, em qualquer que seja a área de atuação, é imprescindível a adoção de uma postura não discriminatória, preconceituosa ou racista. Ao levantarem-se em sala de aula questões como a das cotas raciais, a partir de uma análise crítica do contexto histórico no qual esta política está inserida, poderia ser possível uma mudança de opiniões, aumentando o número de estudantes favoráveis. Afirmamos isso tendo em vista que muitos dos estudantes que apontaram ser desfavoráveis apoiam suas opiniões em argumentos facilmente refutados através de uma simples análise dialética da realidade. 


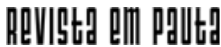

\} POLÍTICA DE COTAS RACIAIS - MENDONÇA, E. S.; ARANHA, M. L. M. \}

DOI: $10.12957 /$ REP.2020.47226

\section{Referências}

BAYMA, F. Reflexões sobre a constitucionalidade das cotas raciais em universidades públicas no Brasil: referências internacionais e os desafios pósjulgamento das cotas. Ensaio: Avaliação e Políticas Públicas em Educação, Rio de Janeiro, n. 75, 2012. Disponível em: http://www.scielo.br/pdf/ensaio/ v20n75/06.pdf. Acesso em: 29 nov. 2017.

BRASIL. Lei no 12.711 de 29 de agosto de 2012. Dispõe sobre o ingresso nas universidades federais e nas instituições federais de ensino técnico de nível médio e dá outras providências. Brasília, DF, 2012. Disponível em: http:// www.planalto.gov.br/ccivil_03/_ato2011-2014/2012/lei/l12711.htm. Acesso em: 16 dez. 2017.

CFESS. Código de ética do/a assistente social - Lei 8.662/93, de regulamentação da profissão. Brasília: Conselho Federal de Serviço Social, 2012. Disponível em: http://www.cfess.org.br/arquivos/CEP_CFESS-SITE.pdf. Acesso em: 18 ago. 2018.

IANNI, O. Raças e classes sociais no Brasil. Rio de Janeiro: Civilização brasileira, 1966.

IANNI, O. Escravidão e racismo. São Paulo: Hucitec, 1988.

JACCOUD, L. Racismo e república: o debate sobre o branqueamento e a discriminação racial no Brasil. In: THEODORO, M. (org.). As políticas públicas e a desigualdade racial no Brasil: 120 anos após a abolição. Brasília: Ipea, 2008.

JANUÁRIO, L. de O. Argumentos a favor das cotas. 2014. Disponível em: https://vestibular.mundoeducacao.bol.uol.com.br/cotas/argumentos-favordas-cotas.htm Acesso em: 19 ago. 2018.

MARCON, F. Distorções Sociais no acesso ao ensino público superior e os fundamentos da proposta de ações afirmativas da UFS. In: Ações afirmativas e políticas inclusivas no ensino público superior: a experiência da Universidade Federal de Sergipe. Sergipe: Editora UFS, 2010.

NEVES, P. S. da C. O contexto de emergência e de consolidação das políticas afirmativas na Universidade Federal de Sergipe. In: Ações afirmativas e políticas inclusivas no ensino público superior: a experiência da Universidade Federal de Sergipe. Sergipe: Editora UFS, 2010.

OLIVEIRA, C. Atlas da violência 2017: negros e jovens são as maiores vítimas. Carta Capital, 5 jun. 2017. Disponível em: https://www.cartacapital.com.br/ sociedade/atlas-da-violencia-2017-negros-e-jovens-sao-as-maiores-vitimas. Acesso em: 20 jan. 2018. 


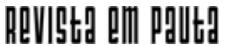

\} POLÍTICA DE COTAS RACIAIS - MENDONÇA, E. S.; ARANHA, M. L. M. \}

DOI: $10.12957 /$ REP.2020.47226

PENA, M. R. G. Ações afirmativas e o princípio da igualdade: a questão das cotas raciais nas universidades públicas. Rio de Janeiro: Escola de Magistratura do Estado do Rio de Janeiro, 2010.

THEODORO, M. A formação do mercado de trabalho e a questão racial no Brasil. In: THEODORO, M. (org.). As políticas públicas e a desigualdade racial no Brasil: 120 anos após a abolição. Brasília: Ipea, 2008.

UFJF. Consciência negra: nem 13\% dos alunos de ensino superior são negros no Brasil. Juiz de Fora - MG: Universidade Federal de Juiz de Fora, 2017. Disponível em: https://www2.ufjf.br/noticias/2017/11/20/consciencia-negranem-13-dos-alunos-de-ensino-superior-sao-negros-no-brasil/. Acesso em: 19 ago. 2018.

VIEIRA, I. Percentual de negros em universidades dobra, mas é inferior ao de brancos. Rio de Janeiro: Agência Brasil, 2016. Disponível em: http://agen ciabrasil.ebc.com.br/educacao/noticia/2016-12/percentual-de-negros-emuniversidades-dobra-mas-e-inferior-ao-de-brancos. Acesso em: 15 out. 2018.

DOI: $10.12957 /$ rep.2020.47226

Recebido em 04 de julho de 2019.

Aprovado para publicação em 04 de novembro de 2019.

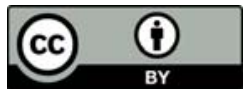

A Revista Em Pauta: Teoria Social e Realidade Contemporânea está licenciada com uma Licença Creative Commons Atribuição 4.0 Internacional. 